\title{
How to Teach Usage of Equipments in a Remote Laboratory
}

\author{
N. Ceren ALPARSLAN \\ Bilkent University \\ Ankara, Turkey \\ Mustafa OZEN \\ Atilim University \\ Ankara, Turkey
}

\author{
Nergiz Ercil CAGILTAY \\ Atilim University \\ Ankara, Turkey \\ Elif AYDIN \\ Atilim University \\ Ankara, Turkey
}

\begin{abstract}
European Remote Radio Laboratory (ERRL) is an elearning project for students, teachers and technicians of the universities who will use the very important devices of this laboratory remotely. These devices are very expensive to buy and can be broken easily while they have been using by the people who does not really know how to use them professionally. As a solution we have developed an e-learning system which aims to support the ERRL learners while studying on how to use equipments in the system. The system is developed according to the electronic performance support systems (EPSS) approach. An EPSS is a computer-based, wellstructured system which improves the performance of individuals. It is an electronic infrastructure that contains, stores and distributes personal (individual) or corporate knowledge to enable people to reach necessary levels of performance in the fastest possible time and with minimum teaching support of other people. This paper discusses how the content for such a system is developed and how this content is interactively used in the EPSS platform. The technical details of the developed EPSS are also discussed in this study. We believe that this paper will help instructional system designers for designing different alternatives to improve learners' performance.
\end{abstract}

Keywords: Electronic Performance Support System, EPSS, Remote Radio Laboratory, non-linear instruction, e-learning.

\section{INTRODUCTION}

European Remote Radio Laboratory (ERRL) is an elearning project serves for students, technicians and engineers who will use the devices of a distance access Radio Frequency (RF) Laboratory. This project is established since the devices that must be used are economically valuable and can easily be broken while they are being used by the learners who do not know how to use them professionally. So, to avoid using them by human interaction, it is decided to develop a distance access RF Laboratory platform. The aim is to provide access to theoretical and particularly practical training and provide access to high-cost and high-technological equipments in radio communications fields via Internet.
One of the requirements in this project is that: the learners in the system should know about the equipments which they will use for studying experiments. Theoretical and practical background should be provided for the learners to be ready to use these equipments in the practical studies and experiments. However, generally, the backgrounds of the learners in such an environment differ. For some learners only a specific feature of equipment might be important where as for the others whole structure could be new. Accordingly, it is hard to pre-define a learning path and content that fit the requirements of all learners. They need to access this system whenever they need help, as long as they need help and they need to query information as much as they need. We believe that, these requirements fit the purposes of an EPSS system. Accordingly, this paper discusses what an EPSS is, main goals, characteristics and components of it. This study also reports the requirements for an EPSS in the ERRL project. Structure of the EPSS developed for the ERRL project and the benefits of the system are also discussed.

\section{BACKGROUND INFORMATION}

There are many definitions and many views of EPSS. For example according to McGraw an EPSS is an integration of artificial intelligence, hypermedia and learning support (CBT) to produce an integrated system that includes intelligent user interface, embedded training, a hypertext online help system and an intelligent advisor/coaching system [1]. Barker and Banerji view an EPSS as a computer-based interactive guidance and information support facility integrated into the normal working environment of an individual or work group to facilitate and/or improve human performance, problem solving capability within some target application domain [2]. According to Barker, EPSS is a computer based environment which helps to improve the skill and knowledge on a particular work. They agree that, EPSS can be embedded with computerbased learning systems to be able to extend the efficiency and effectiveness of the learners on the skills and knowledge about the objective [3]. From all these explanations the most popular and accepted one is Gloria Gery's explanation. According to her, electronic performance support system is an integrated electronic environment that is available to and easily accessible by 
each learner and is structured to provide immediate, individualized on-line access to the full range of information, software, guidance, advice and assistance, data, images, tools, and assessment and monitoring systems to permit job performance with minimal support and intervention by others [4].

\section{MAIN GOALS OF EPSS}

Despite the variations in definitions based on different views and perspectives, there are some common views on the major goal of an EPSS. Gery suggested that the goals of an EPSS were to provide whatever is necessary to generate performance and learning at the moment of need. So, an EPSS is sometimes required to provide far more than traditional training $[5,13]$. It is important to understand that, it is not learning, but performance. It is sometimes desirable to enhance someone's performance without necessarily promoting learning [6].

Another important goal is to provide the necessary information at the time of need. Learners have to reach the information or documentation needed at the moment of need while they are working. So this means that EPSS is different from the traditional learning model. In traditional learning model, learners have to leave their work situations, go to get and receive training and return their works after learning the necessary information. In contrarily, an EPSS is situated in work, means that learners can obtain the information while they are working at their workstations, can be reached at the moment of need, means that they can reach the needed information whenever they wanted, and also, provides high performance of work, means quality of work is getting higher.

In the light of all these information we can say that electronic performance support system is used for [7]:

- $\quad$ Task structuring support: help with how to do a task (procedures \& processes)

- Access to knowledge bases (help learner to find the information needed)

- Alternate forms of knowledge representation ( video, audio, text, image, data)

\section{CHARACTERISTICS OF AN EPSS}

An electronic performance support system can have some or all the following characteristics $[8,9]$ :

Computer-based: EPSS is a computer-based system, which is what the "electronic" indicates in its name.

Access during task: EPSS provides information needed to perform a task at the time the task is to be performed (done).

Used on the job: EPSS provides information to learners at their workstations on the job, so that the learners can reach the needed information while doing their works.

Controlled by the learner: The learner decides when and what information is needed. No teachers to teach something, they learn by themselves, non-linearly. Motivation of the task is not done by others, the motivation is provided again by the learners themselves to accomplish their tasks.

Reduce the need for prior training: The easy availability of the information needed reduces the need for prior training. Also, in prior training, learners must learn linearly all the information to pick up the necessary ones. On the other hand, in EPSS just get the related parts.

Easily updated: The computerized nature of EPSS makes updating faster and easier than in other media such as, prints, video, audio...

Fast access to information: The learners must reach the information needed quickly when it is needed on the job. Irrelevant information is not included: The learners access only the specific, discrete information needed at that instant, instead of going through loads of irrelevant information to find few details needed.

Allow for different levels of knowledge: EPSS must provide minimal information for those who do not want details. The detailed information can also be provided by other links or documentation for those who want.

Allow for different learning styles: EPSS also can provide varied learning styles for more optimal learning. The same information can be presented in visual, textual, and audio formats.

Integrate information, advice and learning experiences: An EPSS can integrate information, advice and learning experiences for the user. For example, the advisory system would ask the learner some questions about what he or she needs to accomplish, then would suggest which procedure to use.

Artificial intelligence: This characteristic is not very rare in EPSS systems right now, but in the future this property will also become widely used in the system.

All of these characteristics are not required to be included in one EPSS. However, some of them are key characteristics of an EPSS such as; computer-based system, access the information during task is performing, used on the job, is controlled by the learner and reduced the need for prior training. In our point of view, these five characteristics are necessarily needed in order to call the system as an EPSS.

\section{COMPONENTS OF AN EPSS}

An EPSS normally has at least the following six components [10]:

An advisory system: a system that must provide support for problem solving, troubleshooting, as well as decision support, analysis and decision-making.

A data/information base: a system that provides support for accessing and searching the information needed to perform a job.

A learning/training support facility: a system that provides support for self directed learning (non-linear) experiences that are task-related and flexible. 
On-line help/reference: a system that provides on-line explanations, demonstrations, advice, references and alternatives for using the software.

Productivity software: a system to provide documentation processors, flowchart drawing tools, graphing tools, so forth.

An end-user interface: a system that provides the user to navigate easily on the system, to access easily the information that is searching, to advice quickly and easily.

These components are the basis of an EPSS. However, there are some different perspectives again. According to Gloria Gery, there can be some additional components such as assessment system, monitoring and feedback system [4]. On the other hand, some of the researchers are eliminated some of these characteristics. For example, according to Raybould, EPSS has four components such as, advisory system, information base, learning experiences or support and productivity software. Accordingly, there is no consensus in the literature about the components of an EPSS [10].

\section{ERRL PROJECT}

Before discussing the requirements for an EPSS in the ERRL project, we would like to briefly discuss the general structure of the ERRL project. Figure 1 shows the main architecture of the project.

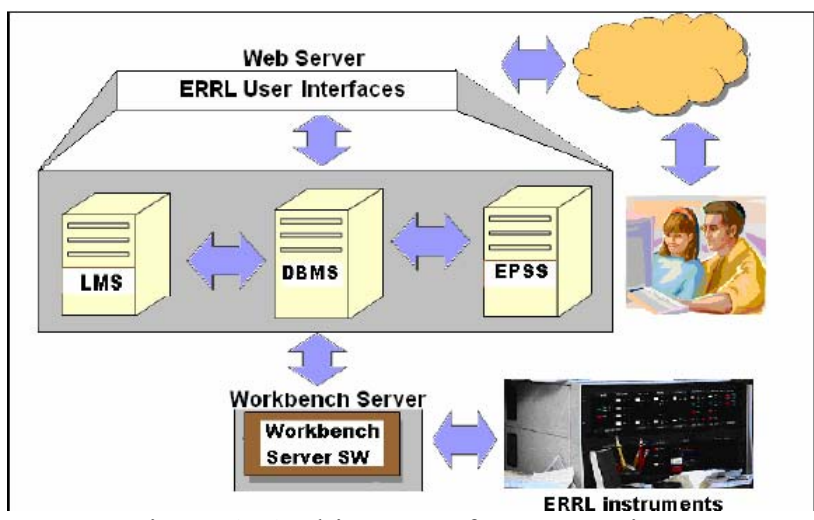

Figure 1: Architecture of ERRL Project

In this architecture learners; students, technicians and the engineers will use the system via web server and workbench server. ERRL user interface have three different services as shown in the Figure 1. First one is the Learning Management System (LMS), is a software package that enables the management and delivery of online content to learners. Most LMSs are web-based to facilitate "anytime, anyplace, any pace" access to learning content and administration. Second one is Database Management System (DBMS), to hold and manage all the necessary data according to the devices and the learners. And the last one is the Electronic Performance Support System (EPSS), which stores and distributes personal (individual) or corporate knowledge to enable people to reach necessary levels of performance in the fastest possible time and with minimum teaching support of other people.

After all these steps the learners will be able to connected to the equipment needed via workbench server real time and can make some experiments according to their needs and get some outputs of their experiments to see the results. Learners are not obligated to learn any equipment's properties in detailed. They can only look for the necessary information, needed at the time of work or experiment. These specifications lead us to develop an electronic performance support system.

\section{REQUIREMENTS FOR AN EPSS IN THE ERRL PROJECT}

To better understand the requirements of the ERRLEPSS we have conducted a requirements analyses study on the possible users of the system. For this we have developed a questionnaire and implemented it to the engineers, students and technicians. The results are summarized in Table 1.

Table 1. Participants

\begin{tabular}{|l|r|c|}
\hline Participant & & \% \\
\hline Engineer & 39 & 23 \\
\hline Technician & 15 & 9 \\
\hline Student & 116 & 68 \\
\hline Total & 170 & \\
\hline
\end{tabular}

$145(85 \%)$ participants are male, and $25(15 \%)$ of them are female. We have asked the subjects, when they are learning a new subject which of the following methods do they prefer. Their responses are shown in Table 2. Most of the participants (53\%) prefer to study with someone who knows the subject well. However, still some participants prefer to study their own $(27 \%)$ or within a group $(20 \%)$.

Table 2. Preferred way of Studying (in groups or individually)

\begin{tabular}{|l|c|c|}
\hline & & $\%$ \\
\hline $\begin{array}{l}\text { Studying with someone who knows } \\
\text { the subject well }\end{array}$ & 90 & 53 \\
\hline Studying on their own & 46 & 27 \\
\hline Studying within a group & 34 & 20 \\
\hline
\end{tabular}

Under this dimension, we also asked their preferred way of studying a new subject in the sense of linear or nonlinear way of studying. Table 3 summarized results of the participants' responses on this question. $61 \%$ of the participants prefer studying a concept by starting from the beginning and go through the chapters one by one in the given order (linear way of studying). On the other hand $17 \%$ prefers reading the chapter(s) that they are interested in and never read rest of the content and $16 \%$ prefer to search on a keyword and than study on that specific topic only or reading the chapter(s) that they are interested in and never read rest of the content (non- 
linear way of studying). Only $10 \%$ have chosen to study on the examples and exercises and never read the rest of the chapters. Accordingly, 33\% preferred non-linear instructions.

Table 3. Preferred way of Studying (in linear or nonlinear order)

\begin{tabular}{|l|c|c|}
\hline & & $\mathbf{\%}$ \\
\hline $\begin{array}{l}\text { Starting a concept from the beginning and } \\
\text { go through the chapters one by one in the } \\
\text { given order }\end{array}$ & 103 & 61 \\
\hline $\begin{array}{l}\text { Reading the chapter(s) that they are } \\
\text { interested in and never read rest of the } \\
\text { content }\end{array}$ & 29 & 17 \\
\hline $\begin{array}{l}\text { Search on a keyword and than study on } \\
\text { that specific topic only }\end{array}$ & 27 & 16 \\
\hline $\begin{array}{l}\text { Trying to understand the end of the } \\
\text { chapter examples and never read the rest }\end{array}$ & 10 & 6 \\
\hline
\end{tabular}

We have asked the participants to order their preferred way of studying a new concept by using a web site. We have multiplied the total number of first place choices by 3 and total number of second place choices by 2 in order to calculate the total scores. The calculated total scores are reported in Table 4. As seen from Table 4, participants mostly prefer to go through the chapters in a given order (linear order) while studying subjects on the web.

Table 4. Preferred way of Studying on the web (in linear or non-linear order)

\begin{tabular}{|l|c|}
\hline $\begin{array}{l}\text { Go through the chapters in a given order one } \\
\text { by one }\end{array}$ & 349 \\
\hline $\begin{array}{l}\text { Reach the information by means of keywords } \\
\text { and read only the chapters you need }\end{array}$ & 246 \\
\hline $\begin{array}{l}\text { By means of questions and answers between } \\
\text { the system and you }\end{array}$ & 191 \\
\hline
\end{tabular}

Table 5 shows the participants' preferences while performing experiments on computer. The score is calculated the same was as in Table 4. Participants mostly prefer interaction, figures on the subjects and story-based instructions follow it.

Table 5. Participants' Preferences while performing an Experiment on Computer

\begin{tabular}{|l|r|}
\hline \multicolumn{1}{|c|}{ Preferred way of Instructions } & \multicolumn{1}{c|}{ Score } \\
\hline Interactive & 1081 \\
\hline Figures on the subjects & 622 \\
\hline Story based & 611 \\
\hline Animations on the subject & 543 \\
\hline Batch jobs & 524 \\
\hline Games related with the subject & 484 \\
\hline Several problems and exercises & 464 \\
\hline Text-based instructions & 417 \\
\hline Sound-based instructions & 332 \\
\hline
\end{tabular}

Main purpose of the ERRL project is to serve several people (students of the universities, engineers and the technicians) all over the world. Accordingly, the background levels of these learners are not the same. This requires a system that provides information for expectations of different learner groups. For example, some learners might be well informed about the equipment but just need to know the meaning of a button or such a little information. On the other hand, others can start learning the equipment for the first time and need any detailed information of the equipment. Accordingly, the system then should provide different levels of information and let its users easily go directly to the requested part.

Some learners will use the equipments while they are doing their daily work in their environment, while other will use the system while doing some experiments on their classes or for their courses. So, the system should be accessible any time while the learners are performing their tasks.

Learners are not necessarily had to follow each instruction in the system provided for different equipments. They shall be able to just reach the necessary information which is needed at the moment of the work. So the system must be self-directed and support also non-linear instructions. Another example is that, if an engineer tries to get some little information about the equipment, and if $\mathrm{s} / \mathrm{he}$ has to go trough the whole the irrelevant content, it might also be annoying. The system must provide the needed information at the moment of need. On the other hand, the system should also support linear instructions and guidance as well. Because from the requirements analyses we understand that the learners prefer both forms.

The system will be used from different countries. So, it is not clear who will use the system and when use it. All the learners can connect to the system whenever they want to. Accordingly, the information-base of the system must also be reachable at the time of need. Another issue is that, technology is growing every day. The radio laboratory equipment can also be adapted to the technological changes. The system then can easily be updated according to the technological changes.

In the light of all these necessities, we have decided to develop an Electronic Performance Support System to be able to meet all these requirements. We believe that an EPSS can meet all these requirements.

\section{INTEGRATED COMPONENTS OF EPSS IN THE ERRL}

ERRL-EPSS includes the following components as shown in Figure 2. The advisory system builds on a question and answer system between the user and the computer. 


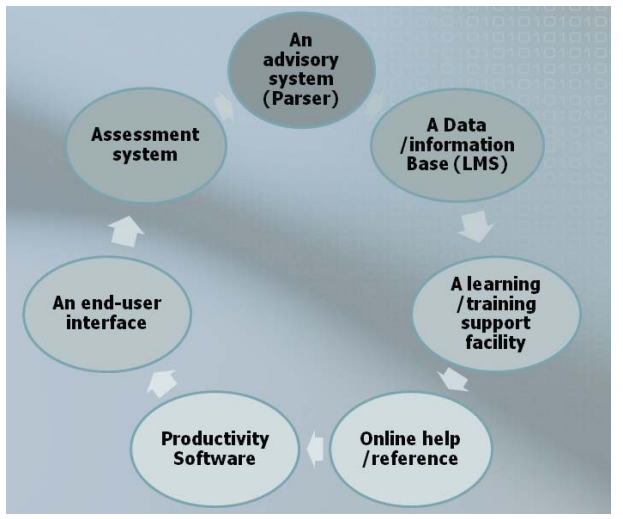

Figure 2: Components of EPSS

By means of a parser, the system gets some questions of learners about the studied equipment. The EPSS parses them and returns some advices in different formats. The advices generally cover the content that is related to the learner's question and previously defined in the EPSS information base.

EPSS information base is formed by means of a database which will support whole system (LMS Database) and the special database of the EPSS to hold some necessary information about the content provided through the EPSS. This structure builds the data/information base of the EPSS. The system will have learning/training support facility because it is not a linear system; it is a self-directed one. Also, our system includes an online help/reference that supports the users on how to use the software easily. It has also an enduser interface to be able to make easy to use of the software. The system is a productivity system because the learners will be able to get some outputs of the pilot experiments on the equipments' screens.

In addition to these six components, our system will also have an assessment system that provides education of individual knowledge or skill and level of expertise either prior to performing a job or in assessing learner competency as shown in Figure 2. The assessment part of the EPSS is developed on top of LMS assessment module [11].

\section{EPSS STRUCTURE OF THE ERRL PROJECT}

EPSS structure of the ERRL project is developed on the pilot part of the project which is designed for Vector Network Analyzer (VNA) equipment of the laboratory. The EPSS can be reached from anywhere in the ERRL project. When the user needs something to learn about the VNA for example then clicks a link to be able to pass the EPSS part of the VNA. Figure 3 is showing the VNA help system. The real picture of the equipments is used in the user interface panel and screen. The right side is blank at the beginning. If the learner needs to learn something about the buttons then it is enough to click on the buttons to see the explanations of that button (See Figure 4, right part).

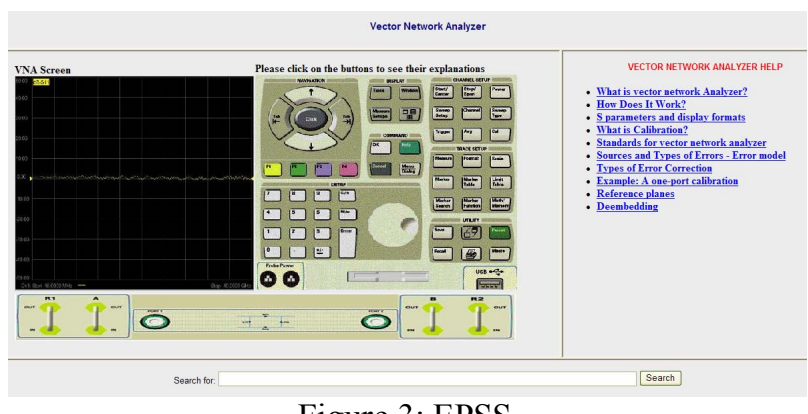

Figure 3: EPSS

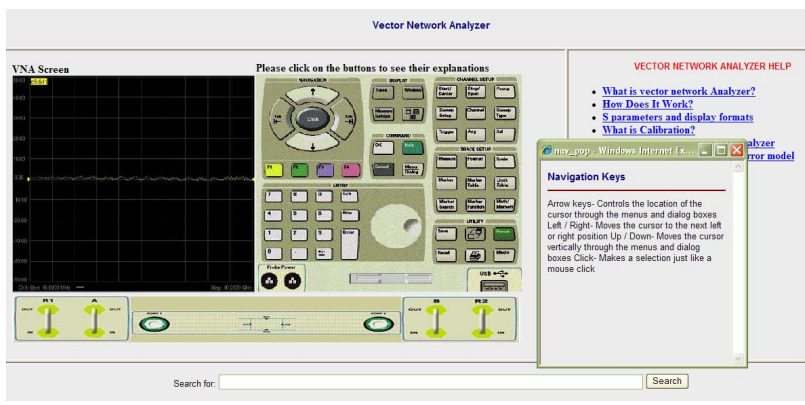

Figure 4: EPSS for ERRL (VNA Equipment)

If the user needs some specific information about the VNA, then s/he can write the keyword or the question to the text field of "Search for:" part of the system. When the "Submit" button is clicked the results of the search will be shown in the right part of the system again. These results will be as links in the form of text documents, videos, audios or the other forms that are available in the Learning Management Systems' (LMS) database.

A basic experiment is also designed to practice how the equipment can be used within an experiment. This experiment is designed as a virtual one as simulating the real data that is previously taken from the equipment and stored in the database. The system supported by two databases. One is to manage the whole information about the equipments, which holds the documentations (specific DBMS of EPSS) and the other types of information and sends them when it is necessary (DBMS of LMS). Figure 4 shows the database structure of the EPSS.

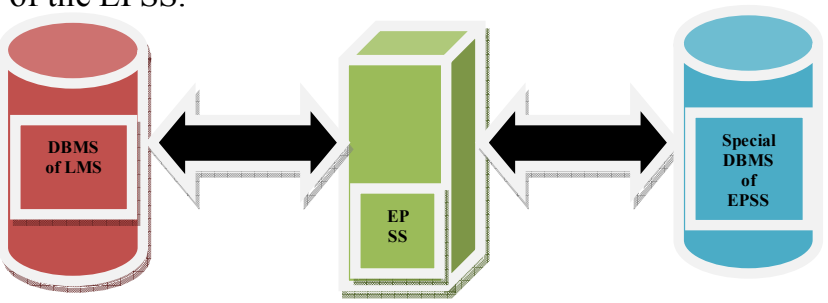

Figure 5: Database Management System Structure of EPSS

LMS Database Management System (DBMS) is integrated to the EPSS system. However, the special database is structured for the EPSS. It is to hold the 
necessary information on equipments of the laboratory. For the development of the EPSS, we used PHP and JavaScrits.

\section{CONCLUSION}

In the technologically developing world, learning strategies are also changed rapidly. Nowadays, individuals prefer to learn things by them-selves and in a non-linear manner [12]. In this project, typical classbased and teacher-based learning is supported by the electronic performance support systems (EPSS). This study reports the main structure and components of the EPSS developed for the ERRL project. We believe that EPSS is a powerful tool which can be developed to support students' learning. We believe that in educational environments there are several places that an EPSS approach would fit perfectly. This will provide an alternative option for the learners to study on their own, on their preferred way of learning as well as request the amount of information that they need. Reach content in the EPSS also an opportunity for the learners to choose the best instruction from set of instructions in the same concept.

\section{References}

[1] McGraw, K.L., (1994). "Electronic Performance Support Systems (EPSS): Integrating AI, Hypermedia and CBT to Enhance the User Performance", Journal of Artificial Intelligence in Education, Vol.5, No.1, p. 3-26.

[2] Banerji, A.K., (1995). "Designing Electronic Performance Support Systems", PhD Thesis, University of Teesside, Middlesbrough, U.K.

[3] Barker, P.G., (1995). "Electronic Performance Support Systems (EPSS)", Special Edition of Innovations in Education and Training International, 32 (1), 1-73.

[4] Gery, G.J., (1995). "Electronic Performance Support Systems (EPSS), How and Why to Remake the Workplace through the Strategic Application of Technology", Gery Performance Press, First Edition, Fourth Printing, 302 pages.

[5] Singhal, M., Prasanna T.S., "Electronic Performance Support Systems (EPSS): An Effective System for Improving the Performance of Libraries". National Center for Science Information, Indian Institute of Science, Bangabre.

[6] Bezanson,W. (2002) "Performance Support Solutions: Achieving Business Goals Through Enabling User Performance", Trafford Publishing, Victoria, Canada.

[7] Sleight, D. A., (1993). "Types of Electronic Performance Support System (EPSS): Their characteristics and Range of Designs", Educational Physiology, Michigan State University.

[8] Stevens, G. E., and Steven, E., (1995). "Designing Electronic Performance Support Tools - Improving Workplace Performance with
Hypertext, Hypermedia and Multimedia", Educational Technology Publications, Englewood Cliffs, N.J., USA.

[9] Schaik, P., Perason, R., Barker, P., "Designing Electronic Performance Support Systems (EPSS) to Facilitate Learning", Innovations in Education and Teaching International, ISSN 14703297.

[10] Raybould, B. (1996). "Performance-Centered Design, Training and Development", Mar 96, Vol. 50, Issue 3, p72, 1p.

[11] Chang, C.C. "The Relationship between the Performance and the Perceived Benefits of using an Electronic Performance Support System", Innovations in Education and Teaching International, Vol. 41, No. 3, August 2004.

[12] Stanley, E., Malcolm, Ph. D., (1998). "Electronic Performance Support Systems (EPSS) Tomorrow, "Where EPSS will go from here"”, Training, March 1998, pp. 64-69.

[13] Bayram, Assoc. Prof Dr. S., (April, 2004). "Provisioning Theoretical Framework of Electronic Performance Support Systems (EPSS) within the Software Application Examples", Turkish Online Journal of Distance Education - TOJDE, Vol.5, No. 2. 